BMJ Open Sport \& Exercise Medicine

\section{It is time to rewrite state youth sports concussion laws}

To cite: Howland J, Hackman $\mathrm{H}$, Torres A, et al. It is time to rewrite state youth sports concussion laws. BMJ Open Sport \& Exercise Medicine 2021;7:e000959. doi:10.1136/ bmjsem-2020-000959

\section{Check for updates}

(c) Author(s) (or their employer(s)) 2021. Re-use permitted under CC BY-NC. No commercial re-use. See rights and permissions. Published by BMJ.

${ }^{1}$ Department of Emergency Medicine, Boston University School of Medicine, Boston, Massachusetts, USA ${ }^{2}$ Injury Prevention Center, Department of Emergency Medicine, Boston Medical Center, Boston, Massachusetts, USA

Correspondence to Dr Jonathan Howland; jhowl@bu.edu

\author{
Jonathan Howland,,$^{1,2}$ Holly Hackman, ${ }^{1,2}$ Alcy Torres, ${ }^{1,2}$ Julia Campbell (D) ,1,2 \\ Jonathan Olshaker ${ }^{1,2}$
}

\section{ABSTRACT}

Between 2009 and 2014, all 50 states and the District of Columbia passed legislation to improve the recognition and management of youth concussed in sports. These laws can include requirements for concussion training for school athletic personnel, concussion education for children and their parents, return-to-play (RTP) procedures, and medical clearance to for RTP. Concussion can impact academic learning and performance in children and adolescents. Postconcussion academic accommodations during recovery can be an important component of secondary prevention for mitigating the sequalae of head injury. Few state youth concussion laws, however, include provision of postconcussion return-to-learn (RTL) accommodations and most of those that do address RTL apply to student athletes only. Concussions may occur in youth who are not participating in organised sports (eg, falls, traffic crashes) and thus may not be subjected to RTL accommodations, even if the state mandates such procedures for athletes. Low income and students of colour may be more likely to have non-sports concussions than their more affluent and white peers, thus potentially creating demographic disparities in the benefits of RTL procedures. State youth sports concussion laws should be revised so that they include RTL provisions that apply to all students, athletes and non-athletes alike.

Traumatic brain injury (TBI) results from a bump, blow or jolt to the head that affects brain function. ${ }^{1}$ In 2014, there were 837000 TBI-related emergency department visits, hospitalisations and deaths among children $\leq 17$ years in the USA. ${ }^{1}$ Of these, 23000 children were hospitalised and 2529 died because of TBI alone or in conjunction with other injuries. ${ }^{1}$

The importance of appropriate management of youth concussion in sports has received significant attention from medical professionals, public health institutions, schools, state legislators, sports organisations, parents and researchers. Between 2009 and 2014, all 50 states and the District of Columbia passed legislation to improve the recognition and management of youth concussed in sports. ${ }^{2}$ These laws can include mandates such as requiring periodic concussion training for school athletic personnel,

\section{Key points}

Return-to-learn procedures can facilitate recovery for children and adolescents reintegrating into school postconcussion.

- Although all states and the District of Columbia have youth sports concussion legislation, few of these laws address return-to-learn.

- All state youth concussion laws should address return-to-learn, with provisions for postconcussion school reintegration for all students, not just student athletes.

educating students and their parents about concussion, return-to-play (RTP) procedures and medical clearance for RTP.

Most TBIs among children are mild and are commonly called concussions. Symptoms of concussion for most youth typically resolve within 28 days of injury, ${ }^{3}$ but symptoms can last longer. One study found that 1 month postconcussion, nearly $25 \%$ of young patients (11-22 years) with concussion reported headache, $>20 \%$ reported fatigue and nearly $20 \%$ reported slower cognitive processing. ${ }^{4}$ While symptomatic, concussion can be a serious health problem that can affect a young person's physical and mental status, with implications for performance of daily activities, including academics. ${ }^{3-14}$ Postconcussion outcomes in children and adolescents include a range of somatic (eg, headache, fatigue), cognitive (eg, attention deficits, forgetfulness, slowed processing) and affective (eg, irritability, disinhibition) symptoms. ${ }^{5611}$ Learning new materials or remembering previously learnt material can pose challenges to students returning to school postconcussion. ${ }^{9}$ School environment (bright lights, computer screens, between-class crowded hallways and noisy cafeterias) can trigger or aggravate postconcussion symptoms. ${ }^{5}$ These symptoms can negatively impact academic performance. In a study that followed 349 children and adolescents (5-18 years) with concussion, actively symptomatic students reported significantly more school-related problems than recovered 
peers. Greater severity of postconcussion symptoms was associated with significantly more school-related problems and significantly worse academic performance, regardless of time since injury. ${ }^{8}$

Return-to-learn (RTL) procedures are intended to mitigate concussion symptoms and accelerate recovery as concussed students reintegrate into school. These protocols can take the form of 'academic adjustments', 'academic accommodations', or 'academic modifications'. 'Academic adjustments' refer to non-formalised environmental adjustments that do not involve classroom work (eg, reduced exposure to light and sound stimuli). ${ }^{9}$ 'Academic accommodations' include extra time for assignments and changes in class and exam schedules. ${ }^{9}$ 'Academic modifications' involve more permanent changes to an education plan, which are formalised in an Individualised Education Plan, pursuant to the Federal Individuals with Disabilities Education Act, or a 504 Plan, pursuant to the Federal Rehabilitation Act and the Americans with Disabilities Act. ${ }^{9}$

Despite the potential impact of concussion on learning and school performance, a 2016 review of state youth concussion laws found that only eight states included provisions for RTL. ${ }^{2}$ Several other states have since amended their youth concussion laws to address this gap. ${ }^{14}$ Most states, however, do not mandate RTL as part of youth concussion legislation. In the absence of mandates, some schools have, by policy or initiative of school personnel, provided RTL protocols for their concussed students.

While acknowledging the lack of definitive efficacy research on components of RTL plans, various medical, public health and research organisations have endorsed RTL strategies for ameliorating individual students' symptoms throughout the recovery period. These organisations include the American Academy of Pediatrics, ${ }^{79}$ the 5th International Conference on Concussion in Sport (Berlin 2016) ${ }^{10}$ the American Medical Society for Sports Medicine $^{11}$ and the Centers for Disease Prevention and Control. ${ }^{12}$ Nonetheless without legislation, schools vary in terms of the consistency, scope and quality of RTL procedures. A 2015 study of RTL procedures in public schools in Washington state (which does not provide for RTL in its youth sports concussion legislation) found that only $12 \%$ of schools reported a formal RTL policy; $67 \%$ had informal policies and $30 \%$ of teachers reported receiving no formal concussion training, even though approximately half reported having had a child with concussion in their class at some point. ${ }^{15}$

Of the eight states identified in the 2016 study as having youth concussion laws that address RTL, only three applied RTL procedures to all students with concussion, without regards to concussion mechanism or precipitating activity. ${ }^{2}$ Some states that have since amended their youth concussion laws to include RTL have mandated it only for student atheletes. ${ }^{14}$ Yet, it is evident that many youth concussions occur during activities other than sports, such as non-sports falls, bicycle and other vehicular crashes, or fighting. Several studies have examined the proportion of medically treated youth concussions that are sports-related (SR) versus non-SR (NSR). One study that used the National Hospital Ambulatory Medical Care Survey, which sampled 600 randomly selected US hospital Emergency Departments (EDs) and ambulatory care clinics, estimated that between 2002 and $2006,70 \%$ of youth (0-19 years) presenting with concussions at hospital EDs and ambulatory care clinics had an NSR concussion. ${ }^{16}$ A second study that examined medical records of a sample of patients $(0-17$ years) treated for concussion between 2012 and 2014 at a large, urban, paediatric hospital and associated suburban practices found that $30 \%$ of concussions were NSR. ${ }^{17}$ A third study that examined medical records of Medicaid-insured patient (0-18 years) treated for concussion at a paediatric accountable care organisation between 2008 and 2017 also found that $70 \%$ of the concussions were NSR. ${ }^{18}$ A fourth study of 13291 children (5-19 years) presenting for TBI at a level 1 trauma centre between 2002 and 2011 found that $71.7 \%$ had NSR injuries. ${ }^{19}$

Differences in estimates of the relative proportions of SR and NSR concussions among children and adolescents may be due to differences in how investigators classified concussions (eg, sports and recreation related vs organised SR) and whether caregivers recorded injury activity as well as mechanism (eg, a fall could occur during an SR or NSR activity) ${ }^{20}$ Regardless of the exact proportions of SR to NSR concussions, all concussed students should have the opportunity to benefit from RTL procedures. As Yeates notes: 'Even if only a small proportion of children with mild TBI suffer negative outcomes, then mild TBI is a serious public health problem'. ${ }^{5}$ As state concussion laws evolve, revisions should include RTL procedures that apply to all students, however their concussion occurred.

Revising state youth concussion laws to mandate RTL provisions for all students may specifically benefit lowincome students and students of colour because there is evidence that these students are less apt than their more affluent or white peers to have SR concussions. ${ }^{17}{ }^{19}$ In a retrospective review of youth concussion mechanisms, Haarbauer-Krupa et al found that children with private insurance were 1.4 (95\% CI 1.25 to 1.62) times as likely to have an SR concussion than children who were Medicaid beneficiaries or who were self-pay. ${ }^{17}$ Non-Hispanic Black children were less likely (RR $0.80 ; 95 \%$ CI 0.71 to 0.91 ) to have SR concussion than non-Hispanic White children. ${ }^{17}$ A similar study of youth concussion mechanisms by Hanson et al found that Medicaid and self-pay children were significantly more likely than children with private insurance to have an NSR concussion $(86 \%$ vs $66 \% ; \mathrm{p}<0.000)$ and that African American children were significantly more likely than Caucasian children to have NSR concussions $(81 \%$ vs $68 \%$; $\mathrm{p}<0.000) .{ }^{19}$

In a 2018 commentary, several prominent scholars of youth concussion have argued that expanding concussion laws to incorporate RTL mandates is not necessary. ${ }^{21}$ These authors note that Colorado and Pennsylvania, 
which do not have RTL legislation, have implemented statewide RTL programmes through collaborations between state Departments of Education and Health. ${ }^{21}$ In their review of state youth concussion laws, Thompson et al noted that Oregon, Pennsylvania and Colorado have strong RTL programmes without legislation. ${ }^{2}$ Nonetheless, these latter authors conclude that legislative action on RTL and improved integration of laws and research are needed. We agree. The passage of RTP legislation by all 50 states and the District of Columbia demonstrates that the political will to address youth concussion exists. Revising these laws to include RTL will ensure that procedures are implemented; it will enhance consistency with best practices and it will provide for accountability in implementation of mandates. Notwithstanding the success of a few states in addressing RTL without legislation, these states are the exceptions. Without legislated mandates under-resourced schools are less apt to implement RTL programmes due to lack of funding and personnel, thus compounding the existing disparities in concussion management due to racial and income differences in SR versus NSR concussions. It is time to revise state laws to: (1) include provisions for RTL and (2) apply these provisions to all students, athletes and non-athletes, regardless of how, when or where their concussion occurred.

\section{Twitter Julia Campbell @juliakcampbell}

Contributors All authors participated equally in the creation, writing and review of the manuscript.

Funding The authors have not declared a specific grant for this research from any funding agency in the public, commercial or not-for-profit sectors.

Competing interests None declared.

Patient consent for publication Not required.

Provenance and peer review Not commissioned; externally peer reviewed.

Open access This is an open access article distributed in accordance with the Creative Commons Attribution Non Commercial (CC BY-NC 4.0) license, which permits others to distribute, remix, adapt, build upon this work non-commercially, and license their derivative works on different terms, provided the original work is properly cited, appropriate credit is given, any changes made indicated, and the use is non-commercial. See: http://creativecommons.org/licenses/by-nc/4.0/.

\section{ORCID iD}

Julia Campbell http://orcid.org/0000-0002-2674-1830

\section{REFERENCES}

1 Peterson AB, Likang X, Daugherty J. Surveillance report of traumatic brain injury-related emergency department visits, hospitalizations, and deaths. 24. US: National Center for Injury Prevention and Control (NCIPC), Centers for Disease Control and Prevention (CDC), Department of Health and Human Services, 2014. https://www.cdc. gov/traumaticbraininjury/pdf/TBI-Surveillance-Report-508.pdf
2 Thompson LL, Lyons VH, McCart M, et al. Variations in state laws governing school reintegration following concussion. Pediatrics 2016;138. doi:10.1542/peds.2016-2151. [Epub ahead of print: 07 Nov 2016].

3 Zemek R, Barrowman N, Freedman SB, et al. Clinical risk score for persistent postconcussion symptoms among children with acute concussion in the ED. JAMA 2016;315:1014-25.

4 Eisenberg MA, Meehan WP, Mannix R. Duration and course of postconcussive symptoms. Pediatrics 2014;133:999-1006.

5 Yeates KO. Mild traumatic brain injury and postconcussive symptoms in children and adolescents. J Int Neuropsychol Soc 2010;16:953-60.

6 Yeates KO, Luria J, Bartkowski H, et al. Postconcussive symptoms in children with mild closed head injuries. J Head Trauma Rehabil 1999:14:337-50.

7 Halstead ME, Walter KD, The Council on Sports Medicine and Fitness. Sport-Related concussion in children and adolescents. Pediatrics 2010;126:597-615.

8 Ransom DM, Vaughan CG, Pratson L, et al. Academic effects of concussion in children and adolescents. Pediatrics 2015;135:1043-50.

9 Halstead ME, McAvoy K, Devore CD, et al. Returning to learning following a concussion. Pediatrics 2013;132:948-57.

10 McCrory P, Meeuwisse W, Dvořák J, et al. Consensus statement on concussion in sport-the $5^{\text {th }}$ international conference on concussion in sport held in Berlin, October 2016. Br J Sports Med 2017;51:838-47.

11 Harmon KG, Clugston JR, Dec K, et al. American medical Society for sports medicine position statement on concussion in sport. Br J Sports Med 2019;53:213-25.

12 Centers for Disease Control and Prevention, US Department of Health and Human Services. Returning to school after a concussion: a fact sheet for school professionals. Available: https://www.cdc. gov/headsup/pdfs/schools/tbi_returning_to_school-a.pdf [Accessed 2 Dec 2020].

13 McAvoy K, Eagan-Johnson B, Halstead M. Return to learn: transitioning to school and through ascending levels of academic support for students following a concussion. NeuroRehabilitation 2018;42:325-30.

14 The Network for Public Health Law. Summary matrix of state laws addressing concussion in youth sports, 2019. Available: https:// www.networkforphl.org/wp-content/uploads/2019/11/Summary-ofState-Laws-Addressing-Concussions-in-Youth-Sports-5-28-19.pdf [Accessed 2 Dec 2020].

15 Lyons VH, Moore M, Guiney R, et al. Strategies to address unmet needs and facilitate return to learn guideline adoption following concussion. J Sch Health 2017;87:416-26.

16 Meehan WP, Mannix R. Pediatric concussions in United States emergency departments in the years 2002 to 2006. J Pediatr 2010;157:889-93.

17 Haarbauer-Krupa J, Arbogast KB, Metzger KB, et al. Variations in mechanisms of injury for children with concussion. $J$ Pediatr 2018;197:241-8.

18 Newton A, Yang J, Shi J, et al. Sports and non-sports-related concussions among Medicaid-insured children: health care utilization before and after Ohio's concussion law. Inj Epidemiol 2020;7:55.

19 Hanson HR, Gittelman MA, Pomerantz WJ. Trends of ED visits, admissions, and deaths for pediatric traumatic brain injury comparing sport and non-sport mechanisms. Inj Epidemiol 2019;6:23.

20 Bryan MA, Rowhani-Rahbar A, Comstock RD, et al. Sportsand recreation-related concussions in US youth. Pediatrics 2016;138:e20154635.

21 Halstead ME, McAvoy K, Brown BE. Expanding concussion laws not necessary for return to learning after concussion. Pediatrics 2016;138. doi:10.1542/peds.2016-3194. [Epub ahead of print: 07 Nov 2016]. 